\section{OP0028 LOW DOSE IL-2 THERAPY CAN RECOVERY TH17/TREG CELL BALANCE IN PATIENTS WITH ANKYLOSING SPONDYLITIS}

D. Xu ${ }^{1}$, J. Fan ${ }^{1}$, Q. Chen ${ }^{1}$, K. Qin ${ }^{1}$, X. Li ${ }^{1}$, C. Gao ${ }^{2} .{ }^{1}$ The Department of Rheumatology, The Second Hospital of Shanxi Medical University, Taiyuan, China; ${ }^{2}$ Department of Pathology, Joint Program in Transfusion Medicine, Brigham and Women's Hospital/Children's Hospital Boston, Harvard Medical School, Boston, United States

Background: Recent studies have shown that increased number of Th17 cells and decreased number of Treg cells in the peripheral blood contribute to ankylosing spondylitis (AS). However, current therapy for AS, including biological agents, immunosuppressant and glucocorticoid, can not correct the imbalance of Th17 and Regulatory T (Treg) cells in AS patients effectively. It has been reported that low dose IL-2 can selectively expand Treg cells and had a critical effect on homeostatic balance between the Th17 and Treg cells.

Objectives: The study is to explore the effect of low dose IL-2 therapy on the balance of Treg and Th17 cells in patients with AS and observe the efficiency and side effects of the therapy.

Methods: Seventeen patients, who met the 1984 modified New York criteria and had evidence of active inflammatory spondylitis (defined as Bath AS Disease Activity Index (BASDAI) score $>4$ ) despite of receiving standard therapy including glucocorticoid, immune-suppressants, biological agents or combination of them, were enrolled. These patients were not only given traditional treatment, but also injected subcutaneously low-dose IL-2 (50 WIU/day for 5 days). Clinical and laboratory indicators were compared before and after IL-2 treatment. The side effects were observed in the course of therapy.

Results: The number of Treg cells significantly increased after the treatment by 1 week $(22.58 \pm 12.80$ vs. $73.46 \pm 33.79, p<0.001)$. At the same time, there was a significantly decrease in the ratio of Th17/Treg cells $(0.67 \pm 0.70$ vs. $0.32 \pm 0.33$, $\mathrm{p}=0.068)$. Besides, Th17 cells were also increased ( $12.83 \pm 9.24$ vs. $19.26 \pm 13.24$, $p=0.054)$. Clinical manifestations were improved after the combination treatment of IL-2 and traditional drugs, especially BASDAI was decreased $(4.57 \pm 0.61$ vs. $1.98 \pm 0.83, \mathrm{P}<0.001)$. No obvious adverse reactions were observed.

Conclusions: Low dose IL-2 therapy can restore and maintain the balance of Th17 and Treg cells in the active patients with AS. Manifestation improved after the combination therapy. The therapy is safe. Further research is needed to investigate long term benefits of low-dose IL-2 therapy.

\section{References:}

[1] Wright $P$, Utriainen L, Milling $S$. Dendritic cells and regulatory $T$ cells in spondyloarthritis. Curr Opin Rheumatol. 2013; 25(4):440-7.

[2] Zambrano-Zaragoza JF, Agraz-Cibrian JM, González-Reyes C, et al. Ankylosing spondylitis: from cells to genes. Int J Inflam. 2013; 2013:501653.

[3] Klatzmann D, Abbas AK. The promise of low-dose interleukin-2 therapy for autoimmune and inflammatory diseases. Nat Rev Immunol. 2015;15(5):28394.

[4] He J, Zhang X, Wei Y, et al. Low-dose interleukin-2 treatment selectively modulates CD4(+) T cell subsets in patients with systemic lupus erythematosus. Nat Med. 2016;22(9):991-3.

Disclosure of Interest: None declared

DOI: 10.1136/annrheumdis-2017-eular.2564

\section{OP0029 EVALUATION OF THE EFFICIENCY OF SACROILIAC JOINTS CORTICOID INJECTIONS UNDER SCAN CONTROL AND ITS RELATIONSHIP WITH THE PRESENCE OR ABSENCE OF SACROILIITIS LESIONS SEEN ON MRI OF PATIENTS WITH SPONDYLOARTHRITIS}

A.M. Devauchelle ${ }^{1}$, O. Vittecoq ${ }^{1}$, T. Lequerre ${ }^{1}$, P. Michelin ${ }^{2}$, F. Vincent ${ }^{2}$. ${ }^{1}$ Rheumatology department of Rouen; ${ }^{2}$ Radiology department of Rouen, rouen, France

Background: Sacroilitis is a common symptom for patients suffering from axial and/or peripheral spondyloarthritis. Several studies have demonstrated that long standing corticosteroid injections of the sacroiliac joints can reduce significantly sacroilitis pain. However, it is difficult to identify predictive factors of good response to the infiltration.

Objectives: Hence, our purposes were to evaluate the benefit from sacroiliac long standing corticosteroid injections and to determine if MRI sacroiliac images could predict infiltration's response.

Methods: This monocentric study was conducted in real-life circumstances between January 2013 and June 2016 from a standardized procedure. Thirty-one patients having inflammatory pain originating from the sacroiliac joints were infiltrated with a long acting corticosteroid (cortivazol) under CT scan guidance. Hence, 56 sacroiliac joints were injected. To be included, patients had to suffer mainly from low back and/or buttock region in the context of axial or peripheral spondyloarthritis defined by the 2009 ASAS criteria. A contrast enhanced MRI was performed if the last MRI dated more than six months before the infiltration. The main clinical outcome was a global benefit expressed by the patient at day 15 after the infiltration (D15), 1 month (M1), 3 months (M3) and 6 months (M6). Results: $44.1 \%$ of patients had a global benefit of at least $50 \%$ at D15, $63.6 \%$ at $\mathrm{M} 1,48.3 \%$ at $\mathrm{M} 3$ and $35.7 \%$ at M6. Besides, there was a decrease of the spontaneous Visual Analog Scale for pain (VAS) of the sacroiliac joint at D15, M1 and M3. Likewise, there was a decrease of the provoked VAS of the sacroiliac at D15, M1, M3 and M6. The decrease of the spontaneous VAS was at least of $50 \%$ for $35.2 \%$ of patients at $\mathrm{D} 15,41.5 \%$ at $\mathrm{M} 1,25.6 \%$ at $\mathrm{M} 3$ and $33.3 \%$ at M6. There was no decrease of the BASDAI, BASFI, ESR, CRP, ASDAS ESR and ASDAS CRP. Moreover, no relationship was found between the efficiency of sacroiliac infiltrations in terms of global benefit as well as of decrease of the VAS of at least $50 \%$ and the presence of sacroilitis images on the MRI. Neither when looking at the different subtypes of sacroilitis lesions (bone marrow oedema, synovitis, osteitis). Among the non active sacroilitis structural lesions (erosions, subchondral sclerosis, bone brigdes...), only fatty involution was statistically more present in the group with a global improvement or a VAS of less than $50 \%$.

Conclusions: Long acting corticosteroid infiltrations of the sacroiliac joints are useful in patients suffering from inflammatory sacroiliitis pain. However, the majority of sacroiliac joints images found on a concomitant MRI does not predict the treatment response except fatty involution that seems to be associated with a lower response. Likewise, composite indexes/scores as well as parameters of systemic inflammation are not relevant for the patients follow up in that indication. Disclosure of Interest: None declared

DOI: 10.1136/annrheumdis-2017-eular.2303

\section{OP0030 INEQUITY IN BIOLOGIC DMARD PRESCRIPTION FOR SPA ACROSS THE GLOBE. RESULTS FROM THE ASAS COMOSPA STUDY}

E. Nikiphorou ${ }^{1}$, D. van der Heijde ${ }^{2}$, S. Norton ${ }^{1}$, R. Landewé ${ }^{3}$, A. Moltó ${ }^{4}$, M. Dougados ${ }^{4}$, F. van den Bosch ${ }^{5}$, S. Ramiro ${ }^{2} .{ }^{1} \mathrm{KCL}$, London, United Kingdom; ${ }^{2}$ LUMC, Leiden; ${ }^{3}$ ARC, Amsterdam, Netherlands; ${ }^{4}$ Paris Descartes University, Paris, France; ${ }^{5}$ Ghent University Hospital, Ghent, Belgium

Background: The value of biologic DMARDs (bDMARDs) in SpA is well recognized but global access to these treatments can be limited due to high cost and other factors.

Objectives: This study explores variation in the use of bDMARDs in SpA across countries and to what extent socio-economic (SE) factors may explain variation. Methods: Patients fulfilling the ASAS SpA criteria in the multi-national, crosssectional ASAS COMOSPA study were studied. Multi-level logistic regression models with random intercept for country were constructed with current use of bDMARDs as the dependent variable. Contribution of socio-economic factors using country health expenditures and gross domestic product (GDP) (all low vs medium/high tertiles) as independent country-level factors, was explored in models adjusted for socio-demographic as well as clinical variables known to determine bDMARD-use in SpA.

Results: In total, 3370 patients from 22 countries were included (mean [SD] age 43 [14] years; $66 \%$ male; $88 \%$ axial disease). Across countries, 1275 $(38 \%)$ were bDMARD users. Crude mean bDMARD-use varied between $5 \%$ (China) to $74 \%$ (Belgium). After adjustment for relevant socio-demographic and clinical variables, important variation in bDMARD-use across countries remained (Figure, $p<0.001$ ). Country-level socio-economic factors, specifically higher health

Eigure kPMARR uptake (\%) by country. Adjusted percentage use shown along with $95 \% \mathrm{C}$ based on models with socio-economic, socio-demographic and clinical variables. Crude BRMARR uptake indicated by the orange squares.

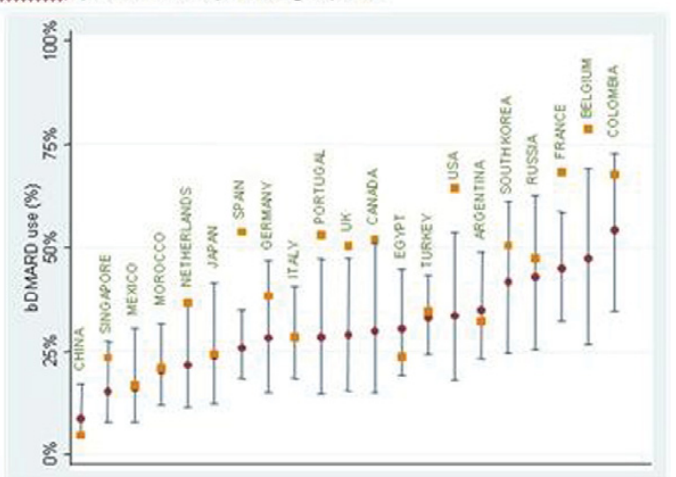

Table, Impact of country socio-economic factors on the use of bPMARDs in a model adjusting for socio-demographic and clinical variables (country included as random effects).

\begin{tabular}{|c|c|}
\hline Independent predictors & $\begin{array}{l}\text { BDMARD use } \\
\text { OR (95\% CI) }(n=2758)\end{array}$ \\
\hline Country health expenditure (US dollars] & $1.91(0.93,3.92)$ \\
\hline Ase (years) & $1.00\{0.99,1.01\}$ \\
\hline Male gender (vs females) & $1.25(1.03,1.52)$ \\
\hline Axial (us peripheral) disease & $1.55(1.09,2.22)$ \\
\hline ASDAS (CRP based) & $0.80\langle 0.73,0.87\}$ \\
\hline Secrofilitis on X-ray & $1.38(1.09,1.74)$ \\
\hline History of extra-articular manifestations & $1.36 \mid 1.13,1.65\}$ \\
\hline $\left.8 \mathrm{ML} / \mathrm{kg}=\mathrm{m}^{2}\right)$ & $1.02|1.00,1.04|$ \\
\hline Total NSAlD score $(0-100)$ in last 3 months & $0.99(0.99,1.00)$ \\
\hline Current CsDMARD use & $0.71(0.58,0.87)$ \\
\hline Past CSDMARD use & $1.98\{1.63,2.41\}$ \\
\hline Past bDMARD use & $2.53\{1.96,3.25\}$ \\
\hline $\begin{array}{l}\text { Edveation /secondary/university vs } \\
\text { primary) }\end{array}$ & $0.75 / 0.51,1.10$ \\
\hline
\end{tabular}

